\title{
Identification and characterization of fluid milk consumer groups
}

\author{
W. S. Harwood and M. A. Drake ${ }^{1}$ \\ Department of Food, Bioprocessing, and Nutrition Sciences, Southeast Dairy Foods Research Center, North Carolina State University, \\ Raleigh 27695
}

\begin{abstract}
Consumption of fluid milk has steadily declined over the last few decades. Understanding the attributes of fluid milk products that are attractive to specific consumer groups may provide a sound basis for education and marketing to encourage increased dairy consumption and reverse the downward trend. The objective of this study was to identify the attributes of fluid milk that specific consumer groups find attractive and attributes that suggest a higher purchase likelihood. An adaptive choice-based conjoint (ACBC) survey was designed to assess attributes of fluid milk. The ACBC survey included Kano, importance, labeling identification, and beliefs questions to determine the key attributes that dictated consumer purchase and consumption. Self-reported purchase habits and attitudes for organic food products were also collected. Attributes in the ACBC exercise included fat content, package type, shelf life, and label claims. Maximum difference scaling was used to rank the importance of attributes in fluid milk that affected purchase. Maximum difference scaling was also used to rank qualities and issues associated with organic milk that were most motivating for those who identified as organic milk consumers. Results were analyzed by univariate and multivariate statistics. A total of 1,163 fluid milk consumers completed the survey, and of those, 434 were regular purchasers of organic milk. The ideal fluid milk from conjoint analysis was $2 \%$ milkfat, organic, packaged in a plastic jug, conventionally pasteurized, and contained no additives or label claims. The belief that "organic milk is healthier" was the most important motivator for purchases of organic milk, followed by the beliefs that "organic milk production encourages ethical treatment of animals" and "organic milk production supports local farms and farmers." Conjoint importance scores of all fluid milk consumers showed that milkfat content was the most important attribute, followed by flavor,
\end{abstract}

Received March 31, 2018.

Accepted June 25, 2018.

${ }^{1}$ Corresponding author: maryanne_drake@ncsu.edu package size, and price. For all milk consumers, designation as organic was ranked as the 8th most important of 14 attributes. Evaluation of these results on both aggregate and individual levels suggest that fluid milk consumers are not a homogeneous consumer group and that underlying consumer groups are led to purchase decisions by specific product features or expectations.

Key words: milk, organic milk, conjoint analysis, Kano, maximum difference scaling

\section{INTRODUCTION}

Fluid milk is a product that is often treated as a dietary staple. However, fluid milk sales have decreased significantly in recent years, with a $2.6 \%$ decline observed in 2016 (DMI, 2017). Several reasons for the decline have been proposed, such as the growing popularity of milk alternatives, flavor concerns, and shelf-life concerns (McCarthy et al., 2017b). Although sales within the fluid milk category are generally in decline, sales of organic milk continue to climb. The US organic industry has increased steadily over the last decade, reaching $\$ 47$ billion in sales in 2016 (OTA, 2017). Dairy is an important part of this movement and is currently the second most purchased organic food category, behind only fruits and vegetables (OTA, 2017). Relatively few studies have sought to identify and profile the typical organic dairy user. McCarthy et al. (2017b) identified that some consumer groups had a preference for organic designation relative to other label claims in fluid milk products. Similarly, consumer choice exercises have identified consumer segments with a preference for organic designation in flavored milk products and other dairy beverages (Kim et al., 2013; Li et al., 2014; Oltman et al., 2015). The preference for organic designation in fluid milk is typically linked to increased willingness to pay a premium price (Smith et al., 2009; Schott and Bernard, 2015). Fluid milk label claims such as pasture-raised and recombinant bovine somatotropin (rbST)-free designations have been similarly associated with greater willingness to pay by certain consumer groups (Kolodinsky, 2008; Wolf et al., 2011). With evidence of consumer interest in mind, further investigation and appropriate valua- 
tion of different features in commercially offered fluid milk products are essential for milk producers in the modern market.

Multiple survey and auction methods have been suggested to be useful for understanding and measuring consumer perceptions relating to commercial products. Conjoint analysis is one such method that is particularly useful because it mimics the real-life trade-off scenarios that consumers encounter in everyday life (Orme, 2010). Conjoint analysis is a survey-based market research technique that uses complex statistical designs to derive the importance of product features using simple rating or choice exercises on randomly assembled product profiles. There are multiple types of conjoint analysis, such as menu-based choice, choicebased conjoint (CBC), and adaptive choice-based conjoint (ACBC), as well as many specific methodological applications for each type. For evaluation of commercial consumer goods, the most commonly used conjoint method is CBC. The CBC surveys are conducted by comparing multiple product profiles at once and simply asking consumers to simulate a typical shopping experience by choosing one of the products from a set. This process is repeated multiple times until trends in consumer choice behavior can be effectively mapped and subjected to utility estimation (Orme, 2010). Although CBC surveys are effectively used market research initiatives, CBC surveys require price to be handled as a discrete level, making realistic price estimation difficult. Furthermore, sizeable CBC surveys may require large amounts of respondents, which can be expensive and demanding of time and resources.

The ACBC surveys are useful because they effectively engage respondents and address concerns associated with CBC because they require fewer responses to estimate utility values (Chapman et al., 2009; Cunningham et al., 2010; Jervis et al., 2012). The ACBC, like CBC, simulates a realistic consumer experience using discrete choice exercises. However, the ACBC software operates by utilizing an algorithm to analyze consumer responses during the survey and adapts upcoming exercises to best investigate the motivators behind consumer choice. In addition to lower sample size requirements, ACBC has been shown to be superior to $\mathrm{CBC}$ in evaluations including pricing attributes (Cunningham et al., 2010; Jervis et al., 2012). The ACBC surveys have been effectively used to profile consumer desires for several food products such as sour cream and bacon, and provided stable estimates of valuation for product features that were tested (Jervis et al., 2012; McLean et al., 2017). Using an ACBC survey, Kim et al. (2013) effectively investigated the effect of brand, packaging, and label claims for commercial chocolate milk products. In this way, ACBC shows its value because it can simultaneously estimate features that are intrinsic to a product such as size or flavor, as well as extrinsic features such as label claims.

Other effective methods for assessing consumer perceptions include Kano model analysis and maximum difference (MaxDiff) scaling. Similar to conjoint analysis, MaxDiff employs the use of trade-off scenarios to determine consumer choice patterns, but lacks the multiattribute model that is used in conjoint. The MaxDiff exercises are useful in research applications because they are easy to administer, easy for respondents to understand, and provide concise rankings and ratings for a list of items. In a MaxDiff experiment, subsets from a master list of items are presented and the respondent is asked to choose the "best" and "worst" option from the set (Louviere and Woodworth, 1990). Following several evaluations, and statistical analysis via multinomial logit or hierarchical Bayesian regression, an easy-to-understand ratio-scaled list of importance for the given attributes is produced. The MaxDiff analysis has been applied in several food studies, including applications for products such as beer, wine, and ground beef (Goodman et al., 2005; Lusk and Parker, 2009; Chrysochou, 2014). McLean et al. (2017) also used MaxDiff exercises to better understand how consumers visually assessed lean-to-fat ratios in commercial bacon products. Unlike MaxDiff and conjoint exercises, Kano model analysis seeks to describe consumer sentiments about product features through assessment of their usefulness or function in response to the degree to which they are implemented (Kano et al., 1984). In practice, questions in the Kano model ask about the consumer's feelings if a product feature is present versus how the how the consumer would feel if the feature was missing. The joint answers from the functional and dysfunctional questions are then used to categorize the utility of the feature in question (Lofgren and Witell, 2008). Categorized Kano results provide valuable data on their own merits, but are particularly useful as a means for complementing and explaining the calculations from methods like conjoint analysis from a more qualitative perspective. Kim et al. (2013) used the Kano model in conjunction with conjoint analysis to understand consumer perspectives for chocolate milk and found agreement between positive Kano classifiers and higher utility values. Kano model analysis has also been applied to numerous other food and beverage products including black beans, eggs, and cottage cheese (Kuo et al., 2014; Wardy et al., 2014; Hubbard et al., 2016).

The aforementioned survey methodologies, whether administered on their own or conjunctively with other methods, have been shown to be useful for profiling and 
understanding food and beverage consumers. Although many studies on fluid milk have addressed features that are attractive in fluid milk, understanding is limited on how exactly these sentiments are linked to the consumer. Furthermore, no holistic assessment has been done of consumers who purchase organic fluid milk that explains purchase behavior, preferences, and belief systems concurrently. The objectives of this study were to identify the unique drivers of liking for fluid milk products, explain motivations for purchase outside of convention, and to compare the differences among different consumer groups.

\section{MATERIALS AND METHODS}

\section{Experimental Overview}

An online survey using ACBC, MaxDiff scaling, and Kano analysis was conducted. Estimation of attribute values was determined using multinomial regression techniques and the values were subjected to cluster analysis for elucidating purchase motivations in unique consumer groups. Participants who completed the entire survey were entered into a drawing to receive one of fifteen $\$ 25$ gift certificates to a local store. All survey procedures were conducted in compliance with North Carolina State University Institutional Review Board regulations.

\section{Survey}

An online survey was developed using Lighthouse Studio (Sawtooth Software version 9.5.3, Orem, UT). The survey was uploaded to a database maintained by the North Carolina State University Sensory Service Center, which consists of over 10,000 consumers. Survey participants $(\mathrm{n}=1,407)$ who were $18 \mathrm{yr}$ of age or older were able to enter the survey. Participants who reported consumption/purchase of fluid milk at least once a month $(\mathrm{n}=1,163)$ were directed to participate in the conjoint analysis exercise and subsequent survey sections. In addition, participants who reported they were at least "occasional" organic consumers, and specifically reported purchase and consumption of organic milk $(\mathrm{n}=434)$ were directed to a supplemental MaxDiff exercise for understanding the principles that motivated organic milk purchase.

An ACBC survey was used. The attributes and levels for this survey (Table 1) were designed to be easily understood by consumers. The ACBC exercise consisted of 6 total attributes with 2 to 5 levels per attribute. The attributes examined in the survey included fat content, milk type, package type, shelf life, label claim, and price. Within fat content, the levels used were skim, $1 \%$ milkfat, $2 \%$ milkfat, and whole milk. Within the milk type attribute, the levels used were conventional, organic, locally farmed, pasture-raised, and organic pastureraised. Within the package type attribute, the levels used were plastic jug and cardboard carton packaging. Within the shelf life attribute, the levels were identified and defined as conventional pasteurization (18-21 d of refrigerated shelf life), ultrapasteurization (50-65 d refrigerated shelf life), and shelf-stable (no refrigeration). Within the label claims attribute, the levels used were rbST-free, docosahexaenoic acid (DHA)-fortified, rbST-free and DHA-fortified, and none. The survey was designed with a single build-your-own (BYO) task, followed by 8 choice tasks with 4 product concepts per task and available responses of "a possibility" or "won't work for me" for each product concept. All product concepts were displayed and compared as half-gallon fluid milk products.

To assess the price attribute in this study, summed pricing was used to account for levels that warranted a price premium. Summed pricing within ACBC surveys has been suggested to generate more realistic product

Table 1. Attributes and levels used in fluid milk conjoint survey

\begin{tabular}{|c|c|c|c|c|c|}
\hline $\begin{array}{l}\text { Fat } \\
\text { content }\end{array}$ & Milk type & $\begin{array}{l}\text { Package } \\
\text { type }\end{array}$ & Shelf life ${ }^{1}$ & $\begin{array}{l}\text { Label } \\
\text { claims }\end{array}$ & Price \\
\hline Skim & Conventional & Plastic jug & $\begin{array}{l}\text { Conventional pasteurization } \\
\text { (HTST; 18-21 d) }\end{array}$ & None & Summed pricing \\
\hline 1\% Milkfat & Organic $(\$ 2.37)$ & $\begin{array}{l}\text { Cardboard } \\
\text { carton }\end{array}$ & Ultrapasteurized $(\sim 30-65 \mathrm{~d})$ & rbST-free $(\$ 0.24)$ & \\
\hline $2 \%$ Milkfat & $\begin{array}{l}\text { Locally farmed } \\
(\$ 1.00)\end{array}$ & & $\begin{array}{l}\text { Shelf-stable (does not have to be } \\
\text { refrigerated until opened) }\end{array}$ & DHA fortified $(\$ 0.48)$ & \\
\hline
\end{tabular}

\footnotetext{
${ }^{1}$ Definitions were explained in terms of refrigerated shelf life.

${ }^{2} \mathrm{DHA}=$ docosahexaenoic acid; rbST $=$ recombinant bovine somatotropin.
} 
concepts (Cunningham et al., 2010). Level components that were given a price premium in this study were the following: organic, locally farmed, pasture-raised, organic pasture-raised, rbST-free, DHA fortified, and rbST-free and DHA fortified. Base price of a fluid milk product and level-specific price premiums were determined heuristically from a survey of fluid milk prices at grocery stores located in Raleigh, North Carolina. Redundant product features, such as organic and rbSTfree, were not counted doubly in price calculation for the product concepts. Within the conjoint exercise, each price premium was figured into the overall price displayed at $\pm 30 \%$ of the determined price. The sum of base price and all applicable price premiums was presented as the displayed price for each product concept. Component prices were shown during the BYO exercise to encourage realistic product builds, but component prices were not shown in the screening or choicetournament exercises. Each product concept in the 8 choice tasks was a random generation of levels within each attribute that differed from the participant's BYO product build by 3 attributes. To refine available levels and tailor subsequent portions of the conjoint survey to each participant, 5 unacceptable and 4 must-have questions were built into the screening portion of the survey, in accordance with recommendations built in to the software (Orme, 2009). The screening task was followed by a 10 -question choice task tournament section. A maximum of 20 product concepts was brought into the tournament section, with 3 concepts per choice task.

Two MaxDiff exercises were implemented in the survey following the conjoint exercise. The first MaxDiff consisted of 14 fluid milk attributes and was asked to all fluid milk consumer respondents $(\mathrm{n}=1,163)$. Although conjoint results effectively characterize consumer choice between levels within the same attribute and compare attributes via calculated importance scores, MaxDiff scaling was employed with the goal of providing direct comparisons across attributes. These MaxDiff scores were analyzed within the conjoint-determined clusters to help further characterize unique consumer groups. The exercise was designed as 8 sets of best-worst questions, with 5 randomly displayed attributes per set. Respondents were asked to choose a single attribute as "most important" and a single attribute as "least important" for each set. In addition, a second MaxDiff exercise was administered to respondents who self-reported themselves as organic milk purchasers/ consumers $(\mathrm{n}=434)$ to better understand the underlying motivations for organic purchase of milk and dairy products. This task was asked at the end of the survey and involved 12 qualities/issues related to organic dairy purchase. The design of the second MaxDiff exercise matched the parameters of the first MaxDiff exercise.

Kano questions were asked after the first MaxDiff exercise; questions contained the same elements as the conjoint survey, with questions about all-natural, GMO-free, humanely raised, branded, protein-fortified, lactose-free, and vitamin fortified milks added. All fluid milk survey respondents ( $\mathrm{n}=1,163)$ participated in Kano analysis questions. Respondents were asked about milk attributes in both a constructive (for example, "A fluid milk product that is organic") and a reductive form (for example, "A fluid milk product that is not organic"). Response options for each question included "I will like it," "I must have it," "I do not care," "I can live with it," and "I will dislike it" and were used to determine classification for the given attribute (Xu et al., 2009). Kano classifications included the following: attractive: typically unexpected by consumer and result in increased satisfaction when fulfilled; must-have: expected by consumer and lead to dissatisfaction if not fulfilled; one-dimensional: a linear relationship exists between fulfillment and satisfaction; rejecter: consumers are indifferent if the feature is not present and dissatisfied if it is present; and indifferent: consumer is not interested or affected by the feature, whether it is present or absent.

\section{Statistical Analysis}

Individual utility scores from the conjoint survey, as well as MaxDiff scores were determined via hierarchical Bayesian (HB) regression. Additionally, root likelihood values were determined for each respondent from the conjoint survey and respondents that received an root likelihood value of 0.333 or lower were removed to ensure quality data were collected and reported. To analyze mean values and test for significant differences between utility scores and importance scores, a one-way ANOVA with Fisher's least significant difference (95\% confidence) was applied. Cluster analysis of individual utility scores was performed with XLSTAT (version 19.5.2018, Addinsoft, Paris, France) using Euclidean distances and Ward's linkage to categorize similar respondents into groups. Kano questions were evaluated according to the model proposed by Kano et al. (1984). Utilization of correspondence analysis (CA) was suggested by Lillestøl (1991) as a viable method for analysis of categorized Kano model results for elucidating product sentiments not captured by traditional Kano model characterization and was applied to Kano results. Count data from Kano analysis were subjected 
to CA in XLSTAT to further characterize the consumer clusters derived from the conjoint exercise. All analyses were performed at $95 \%$ confidence $(P<0.05)$.

\section{RESULTS AND DISCUSSION}

\section{Conjoint Survey}

No respondents from the conjoint exercise had a root likelihood value below 0.333 , so all responses were used in $\mathrm{HB}$ regression analysis. Utility estimates from $\mathrm{HB}$ analysis are reported as zero-centered differences and higher scores indicate relatively more appealing levels within an attribute (Orme, 2010). Based on average utility estimations, the ideal fluid milk build for the milk consumers surveyed $(\mathrm{n}=1,163)$ was a $2 \%$ organic milk that was conventionally pasteurized, had no label claims, and was packaged in a plastic jug (Table 2). Price was the most important attribute $(P<0.05)$, followed by fat content $(P<0.05)$, milk type and shelf life, which were at parity $(P>0.05)$, and finally, label claims and packaging, which were at parity $(P>0.05)$ (Figure 1). Within the fat content attribute, a preference for reduced-fat milks was observed in the overall population, with $2 \%$ milkfat receiving the highest utility $(P<0.05)$, followed by $1 \%$ milkfat. Skim milk and whole milk received lower utility scores by a significant margin $(P<0.05)$ (Figure 1$)$. Consumer preference for reduced-fat fluid milks mirrors the breakdown of current market volume shares by fat content in the commercial fluid milk category (DMI, 2017). Consumer sentiments regarding packaging type were of low importance overall; however, the overall population gave a higher average utility to plastic jug packaging than for cardboard cartons $(P<0.05)$. Regarding milk type levels, respondents displayed generally higher utilities toward products outside of the convention fluid milk option; specifically, organic milk received the highest utility score $(P<0.05)$, followed by locally farmed milk. Conventional milk received the lowest utility score within the milk type attribute $(P<0.05)$. Consumer interest for locally farmed milk is likely due to the fact that the "local" designation is often associated with environmental benefit or support for the local economy (Zepeda and Leviten-Reid, 2004). In addition, McCarthy et al. (2017b) showed that environmental concerns were a primary reason consumers chose plantbased milk alternatives instead of fluid milk. Results from that study, coupled with the relatively high utility for local designation found in this study, suggest that promotion of local designation in fluid milk may be important in dissuading some consumers from exploring fluid milk alternatives. Regarding pasteurization method, conventional pasteurization $(\sim 18-21 \mathrm{~d}$ of shelf life) received the highest utility score $(P<0.05)$, followed by ultrapasteurization. For the label claims attribute, the overall population gave the "none" option the highest utility $(P<0.05)$, indicating minimal interest in added components such as DHA or rbST-free status. Although rbST-free labeling had a significantly lower utility than the "none" option, it should be noted that the preference for organic milk expressed by the overall population may have been influenced by the understanding that organic designation includes rbST-free as a component. These sentiments were reported by Bernard and Bernard (2009), who showed that many fluid milk consumers do find an added value from rbST-free designation, but often opt to pay the premium for organic instead because of perceived added value from other aspects related to organic labeling.

Raw utility scores derived from the ACBC survey were subjected to k-means clustering and 4 distinct consumer groups were identified (Figure 2). Clusters were given the following names heuristically based on their results from the exercises throughout the study: the premium cluster $(\mathrm{n}=352)$, opportunistic cluster $(\mathrm{n}=393)$, value cluster $(\mathrm{n}=234)$, and the basics cluster $(\mathrm{n}=184)$. Overall, each cluster showed similar trends in allotted

Table 2. Ideal fluid milk product builds for the total population $(\mathrm{n}=1,163)$ and for segmented consumer clusters

\begin{tabular}{|c|c|c|c|c|c|}
\hline Cluster & Fat content & Milk type & $\begin{array}{l}\text { Package } \\
\text { type }\end{array}$ & Shelf life & $\begin{array}{l}\text { Label } \\
\text { claims }\end{array}$ \\
\hline Overall & $2 \%$ Milkfat & Organic & Plastic jug & $\begin{array}{l}\text { Conventional pasteurization } \\
(18-21 \mathrm{~d})\end{array}$ & None \\
\hline Premium cluster $(\mathrm{n}=352)$ & $2 \%$ Milkfat & $\begin{array}{l}\text { Organic pasture- } \\
\text { raised }\end{array}$ & $\begin{array}{l}\text { Cardboard } \\
\text { carton }\end{array}$ & $\begin{array}{l}\text { Conventional pasteurization } \\
\text { (18-21 d) }\end{array}$ & None \\
\hline $\begin{array}{l}\text { Opportunistic cluster } \\
(\mathrm{n}=393)\end{array}$ & $2 \%$ Milkfat & Locally farmed & Plastic jug & $\begin{array}{l}\text { Conventional pasteurization } \\
(18-21 \mathrm{~d})\end{array}$ & None \\
\hline Basics cluster $(\mathrm{n}=184)$ & $2 \%$ Milkfat & Conventional & Plastic jug & $\begin{array}{l}\text { Conventional pasteurization } \\
(18-21 \mathrm{~d})\end{array}$ & None \\
\hline
\end{tabular}




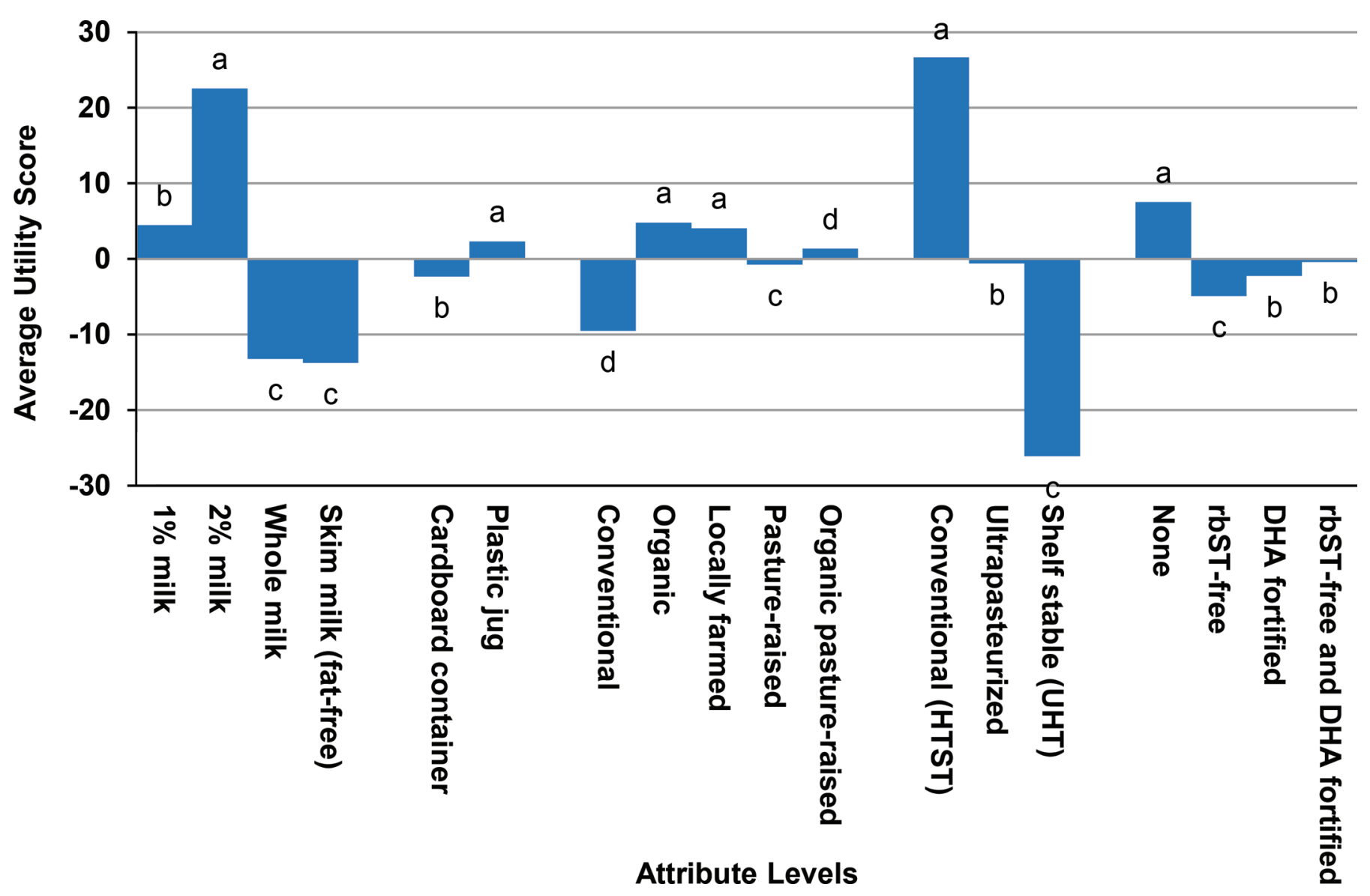

Figure 1. Utility scores for attribute levels for the total population $(\mathrm{n}=1,163)$ from the fluid milk conjoint survey. Zero-centered utility values for levels within attributes. Different letters within attribute categories $(\mathrm{a}-\mathrm{d})$ indicate significant differences $(P<0.05)$ for the total population. DHA = docosahexaenoic acid; rbST = recombinant bovine somatotropin. Color version available online.

importance for fluid milk attributes, with an increased price importance corresponding to a proportional decrease in importance for all other attributes (Figure 3). Several studies have suggested that price sensitivity for fluid milk primarily mirrors consumer disposable income (Jones et al., 2003; Alviola and Capps, 2010). Although a slight trend appeared to be present between income and price sensitivity for consumer clusters in this survey, no difference was observed in proportion of respondents that fell into each income bracket within the clusters $(P>0.05)$. These results suggest that factors outside of price such as consumer demographics, fluid milk product availability, past experience, and belief systems may play a part in purchase habits for consumer subgroups (Zepeda et al., 2003; McCarthy et al., 2017b). Premium cluster $(\mathrm{n}=352)$ respondents placed significantly higher importance on all attributes outside of price $(P<0.05)$ and were least price sensitive, compared with other groups (Figure 4). In addition, premium respondents were defined by a preference for fat-containing fluid milk products (relative aversion to skim milk), high utility for organic/pasture-raised products, and preference for conventionally pasteurized fluid milk products. Opportunistic cluster $(\mathrm{n}=$ 393) respondents were primarily driven by price and showed minimal discrimination between different fluid milk products and options, although a preference for locally farmed milk was expressed. Value cluster ( $\mathrm{n}=$ 234) respondents were defined by high price sensitivity, a relative aversion to whole milk, and preference for locally farmed milk. Basics cluster $(\mathrm{n}=184)$ respondents showed high price sensitivity, the highest approval for conventional milk $(P<0.05)$, and were significantly more likely $(P<0.05)$ than other groups to choose the "none" option for label claims.

The utilities derived from the conjoint analysis exercise successfully identified unique purchase habits for the identified clusters; however, assessment of the demographic and usage data further explained the motivations and restrictions experienced by those groups 
(Figure 2). Evaluation of demographic information by cluster revealed that respondents in the premium cluster were defined by relatively high annual income, high education, and a greater likelihood of reporting a lifestyle that includes frequent exercise and a healthy diet. Furthermore, the premium cluster had a high frequency of respondents who self-reported as organic consumers. This might explain why the premium cluster was the least price sensitive and most likely to explore purchase of organic and other value-added fluid milk products. Similar demographic breakdown and increased willingness to pay for organic fluid milks was also observed by Bernard and Bernard (2009) during auction-style experiments of fluid milk consumers. The opportunistic cluster was demographically similar to the premium cluster in terms of income, organic use, and education, but was more diverse with respect to sex, race, and exercise/dietary habits. The combination of demographic qualities and conjoint analysis results from the opportunistic cluster suggest that this group (the largest identified cluster in this study) consists of consumers who have an income that allows them to explore added-value product features, but generally maintain a sense of price-sensitivity and lean toward convention with regard to fluid milk purchase. The value and basics clusters had similar purchase habits in the conjoint exercise, and were defined by high price sensitivity. In addition, both clusters had a significantly lower percentage of consumers who self-identified as organic consumers compared with the premium and opportunistic clusters. Compared with basics cluster respondents, the value cluster had more $(P<0.05)$ Caucasian respondents and more $(P<0.05)$ female respondents; conversely, the basics cluster had more $(P<$ $0.05)$ non-Caucasian respondents than any other group. Furthermore, the basics cluster was characterized by respondents who reported a generally lower income, lower age, and less focus on diet and exercise compared

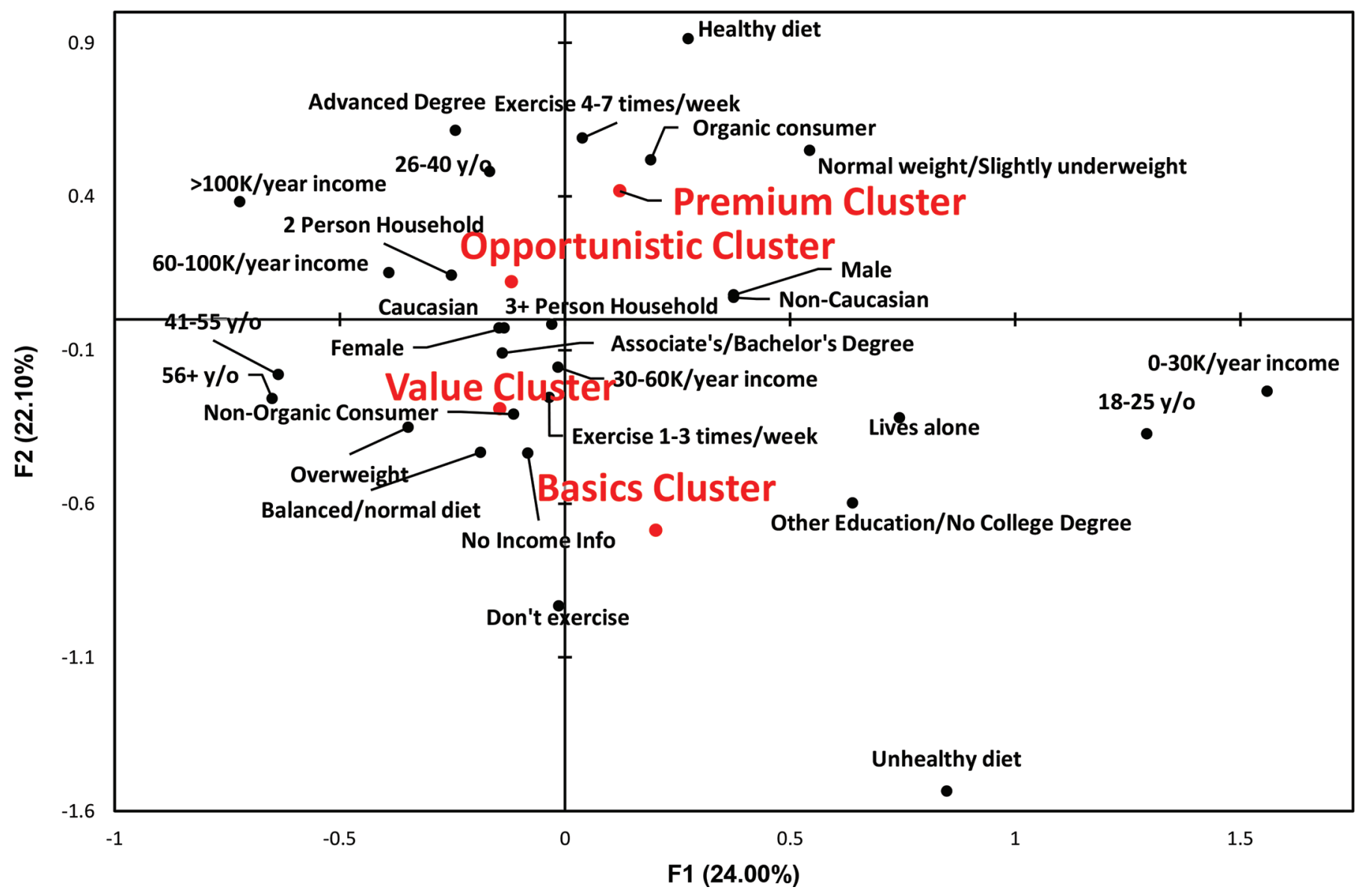

Figure 2. Multiple correspondence analysis of demographic features for fluid milk consumer clusters ( $\mathrm{n}=1,163$ total) derived from k-means clustering of individual utility scores. Household income is expressed numerically in thousands of US dollars earned per year (K). Age group is expressed in years old (y/o). Color version available online. 


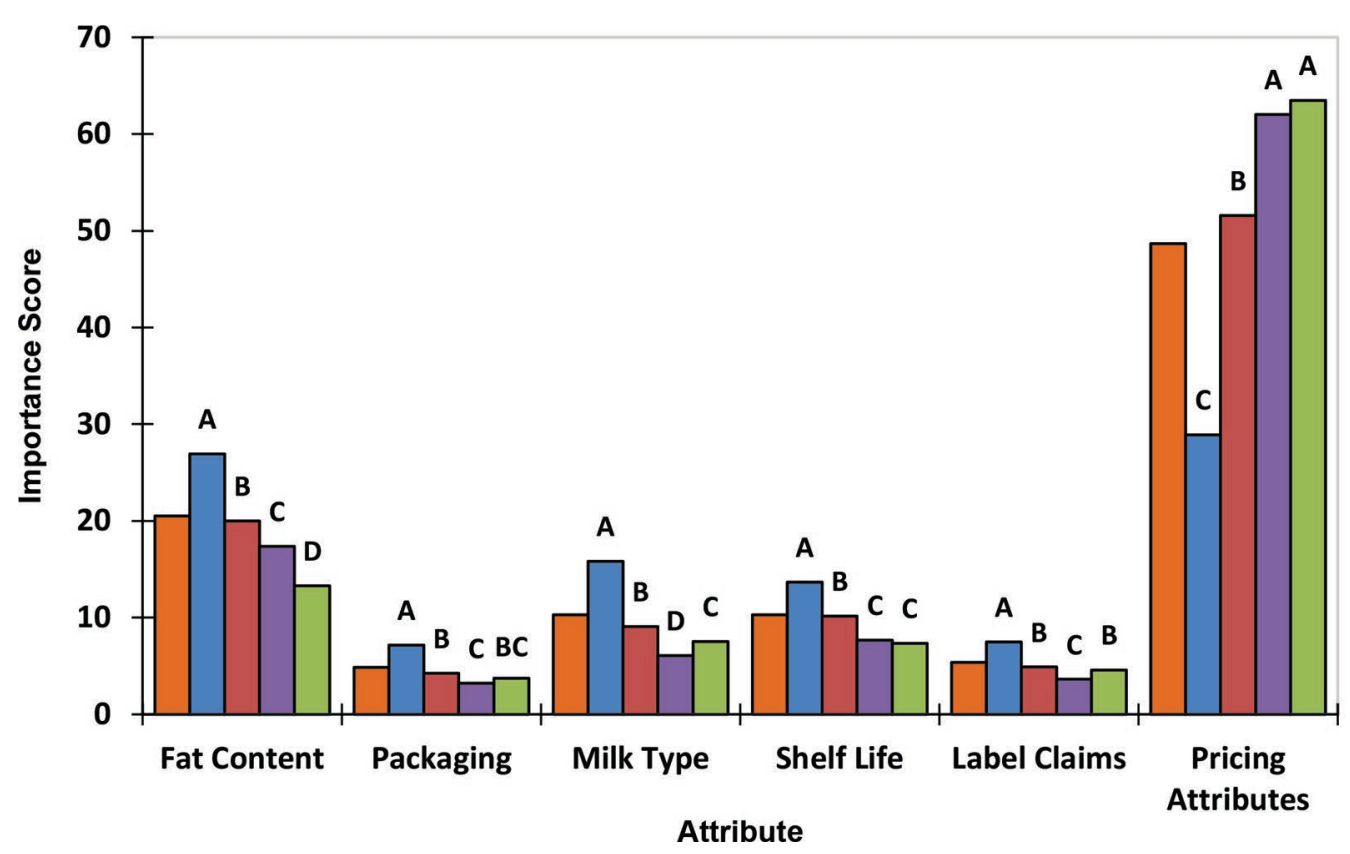

$\square$ Overall $(n=1163)$

$\square$ Premium Cluster $(n=352)$

$\square$ Opportunistic Cluster ( $n=393)$

$\square$ Value Cluster $(\mathrm{n}=\mathbf{2 3 4})$

$\square$ Basics Cluster $(\mathrm{n}=184)$

Figure 3. Attribute importance scores from fluid milk conjoint survey for segmented consumer clusters. Different letters within attributes (A-D) indicate significant differences between clusters $(P<0.05)$. Sum of importance score values for each cluster is 100 points total, and scores are interpreted as ratio-scaled values. Color version available online.

with other groups. The similarities between the value and basics clusters with respect to their conjoint results suggest that demographics may not be an effective determinant of fluid milk purchase for all consumer groups (Zepeda et al., 2003; Chang et al., 2011).

\section{Maximum Difference Scaling}

In the survey design, all fluid milk consumers $(\mathrm{n}=$ $1,163)$ were asked to participate in a MaxDiff exercise for scaling fluid milk product components (Table 3). Overall, MaxDiff scores for the general population matched very closely with the overall conclusions drawn from the conjoint exercise, suggesting that stable consumer sentiments exist. The top 3 attributes in MaxDiff scaling for the overall population $(\mathrm{n}=1,163)$ were, in order: "milk that has the fat content I usually buy," "milk that tastes good," and "milk that is low in price." One notable difference from conjoint results was that "milk that is low price" was rated as only the

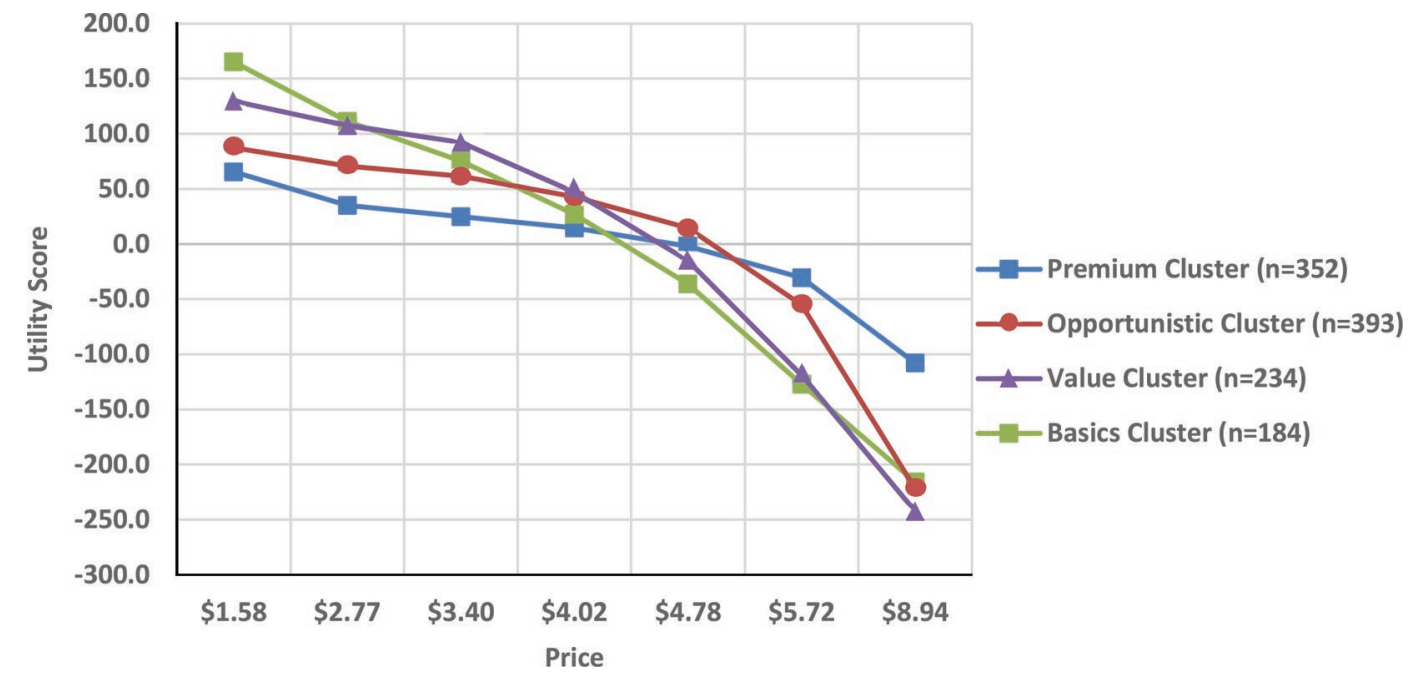

Figure 4. Price sensitivity for fluid milk products by segmented consumer cluster. Color version available online. 
Table 3. Maximum difference scaling of fluid milk attributes by cluster ${ }^{1}$

\begin{tabular}{|c|c|c|c|c|c|}
\hline Label $^{2}$ & $\begin{array}{c}\text { Overall } \\
(\mathrm{n}=1,163)\end{array}$ & $\begin{array}{l}\text { Premium } \\
\text { cluster } \\
(\mathrm{n}=352)\end{array}$ & $\begin{array}{c}\text { Opportunistic } \\
\text { cluster } \\
(\mathrm{n}=393)\end{array}$ & $\begin{array}{c}\text { Value } \\
\text { cluster } \\
(\mathrm{n}=234)\end{array}$ & $\begin{array}{c}\text { Basics } \\
\text { cluster } \\
(\mathrm{n}=184)\end{array}$ \\
\hline Milk that is organic & 4.95 & $8.32^{\mathrm{a}}$ & $5.44^{\mathrm{b}}$ & $2.00^{\mathrm{c}}$ & $1.23^{\mathrm{c}}$ \\
\hline Milk that is $\mathrm{rbST} / \mathrm{rBGH}$-free & 3.73 & $5.25^{\mathrm{a}}$ & $4.56^{\mathrm{a}}$ & $1.91^{\mathrm{b}}$ & $1.35^{\mathrm{b}}$ \\
\hline Milk that is GMO-free & 3.25 & $4.89^{\mathrm{a}}$ & $3.85^{\mathrm{b}}$ & $1.60^{\mathrm{c}}$ & $0.91^{\mathrm{c}}$ \\
\hline $\begin{array}{l}\text { Milk that has the fat content I usually buy } \\
\text { (skim, } 1 \%, 2 \% \text {, whole) }\end{array}$ & 16.55 & $15.04^{\mathrm{c}}$ & $16.30^{b}$ & $18.19^{\mathrm{a}}$ & $17.90^{\mathrm{a}}$ \\
\hline $\begin{array}{l}\text { Milk that comes in the package size I usually buy } \\
\text { (e.g., gallon, half gallon) }\end{array}$ & 12.07 & $9.10^{\mathrm{c}}$ & $11.61^{\mathrm{b}}$ & $14.98^{\mathrm{a}}$ & $15.03^{\mathrm{a}}$ \\
\hline Milk that has a long shelf life ( $>18 \mathrm{~d}$ in refrigerator) & 9.17 & $7.92^{\mathrm{b}}$ & $8.35^{\mathrm{b}}$ & $11.01^{\mathrm{a}}$ & $10.98^{\mathrm{a}}$ \\
\hline Milk that is low in price & 12.07 & $8.50^{\mathrm{c}}$ & $11.17^{\mathrm{b}}$ & $15.42^{\mathrm{a}}$ & $16.56^{\mathrm{a}}$ \\
\hline Milk that tastes good & 15.86 & $14.91^{\mathrm{c}}$ & $15.68^{\mathrm{b}}$ & $16.78^{\mathrm{a}}$ & $16.88^{\mathrm{a}}$ \\
\hline Milk fortified with vitamins/minerals & 6.98 & $7.15^{\mathrm{ab}}$ & $7.30^{\mathrm{a}}$ & $6.44^{\mathrm{b}}$ & $6.68^{\mathrm{ab}}$ \\
\hline Milk that is lactose-free & 1.63 & $1.97^{\mathrm{a}}$ & $1.86^{\mathrm{ab}}$ & $1.12^{\mathrm{c}}$ & $1.16^{\mathrm{bc}}$ \\
\hline Milk that is name brand & 1.13 & $1.57^{\mathrm{a}}$ & $0.97^{\mathrm{b}}$ & $0.82^{\mathrm{b}}$ & $1.02^{\mathrm{b}}$ \\
\hline Milk that is store brand & 1.98 & $1.69^{\mathrm{c}}$ & $1.77^{\mathrm{bc}}$ & $2.19^{\mathrm{b}}$ & $2.71^{\mathrm{a}}$ \\
\hline Milk that has a higher protein and calcium content & 6.54 & $7.25^{\mathrm{a}}$ & $6.61^{\mathrm{ab}}$ & $5.61^{\mathrm{c}}$ & $6.24^{\mathrm{bc}}$ \\
\hline Milk that comes from pasture-raised cows & 4.08 & $6.44^{\mathrm{a}}$ & $4.53^{\mathrm{b}}$ & $1.94^{\mathrm{c}}$ & $1.34^{\mathrm{c}}$ \\
\hline
\end{tabular}

${ }^{\mathrm{a}-\mathrm{c}}$ Means in a row with a different superscript letter are different $(P<0.05)$.

${ }^{1}$ Sum of values in each column is 100 total points, and results are interpreted as ratio-scaled values.

${ }^{2} \mathrm{rbST}=$ recombinant bovine somatotropin; $\mathrm{rBGH}=$ recombinant bovine growth hormone; GMO $=$ genetically modified organism.

third most attractive feature, suggesting that fluid milk consumers either overstated the importance of price in the conjoint exercise, or have a reactionary response to explicitly listed price. An additional explanation may be that consumers do not associate fat content or taste with a price premium, and therefore feel price is a secondary concern to the more direct goal of buying a product that meets their tastes. Results in this study agree with previous literature which has shown that fluid milk consumers are typically rigid in their purchase of specific fat contents, although consumers often show a preference for fluid milks with different fat contents than those they typically purchase in blinded tastings (Bakke et al., 2016; McCarthy et al., 2017a,b). Of the 14 listed attributes, organic designation was rated as the 8th overall attribute, receiving a 4.95\% MaxDiff score. Although this seems at odds with the conjoint results that identified organic designation as an ideal product feature, it should be noted that the importance of organic is being compared with product-defining features such as fat content and acceptable flavor in the MaxDiff exercise. Within the conjoint results, similar conclusions can be drawn, with the milk type attribute being ranked third in importance behind price and fat content.

When analyzed by cluster, distinct similarities and differences were observed. For each cluster, the top 2 fluid milk features were fat content and flavor, respectively, and were followed by either package size or low price to round out the top 4 features. The premium cluster differentiated itself from other clusters with the rating of organic in the fifth position, receiving a MaxDiff score of $8.5 \%$, which was significantly higher $(P$ $<0.05)$ than any other group; additionally, premium cluster respondents gave significantly more importance to pasture-raised and GMO-free designation compared with other groups, and put less importance on low price $(P<0.05)$. The opportunistic cluster's MaxDiff scores were less directional than other groups. Save for vitamin content, the opportunistic cluster did not exhibit the highest or lowest score for any fluid milk feature. Although ultimately unclear, these results suggest consumers in the opportunistic cluster may be interested in product details outside of conventional store-brand fluid milks, but only on a situational basis. The value and basics clusters allotted the greatest importance to price $(P<0.05)$, corroborating the conjoint analysis results. They also placed a significantly higher importance than the premium and opportunistic clusters on features such as package size and long shelf life, suggesting a singular focus on low price and satisfaction of only basic utility for their fluid milk purchases. Interestingly, the interest in long shelf life determined by the MaxDiff exercise was not reflected in the conjoint results. Low utility of ultrapasteurized milk products is likely due to a lack of familiarity with ultrapasteurized fluid milk products, or from lack of understanding of the flavor effect imparted by ultrapasteurization (Oupadissakoon et al., 2009; Lee et al., 2017). In addition, the basics cluster had the highest MaxDiff score for milk that was store brand. This, in conjunction with the low score for organic, might suggest that some consumers associate 
store brand fluid milk products with a lower likelihood of value-added inclusion and an associated price markup.

Consumers who reported at least occasional purchase/consumption of organic milk and dairy products were directed to an additional MaxDiff exercise with the goal of understanding the underlying motivations for organic dairy purchases (Table 4). Demographically, respondents who self-classified as organic milk and dairy users $(\mathrm{n}=434)$ showed marked differences from nonorganic consumers $(\mathrm{n}=729)$. In terms of age, a higher proportion $(P<0.05)$ of respondents were between 25 and $40 \mathrm{yr}$ of age, and a lower proportion $(P<0.05)$ of respondents were aged $56 \mathrm{yr}$ or older in the organic user group compared with the nonorganic group. Evidence also indicated that there were trends in ethnicity regarding organic use, with a higher proportion $(P<0.05)$ of non-Caucasian respondents and a lower proportion of Caucasian respondents within the organic user group compared with the nonorganic group. The trend of non-Caucasian dairy consumers showing increased interest in organic products is consistent with nationwide trends for Asian, Hispanic, and "other" ethnic groups to be more likely purchasers of organic fluid milk (Alviola and Capps, 2010). Age has been found to be unrelated to organic purchase likelihood and purchase frequency (Paul and Rana, 2012); however, results in this study suggest age may play a part in organic dairy purchase. No other demographic factors significantly differentiated organic and nonorganic respondents, although questions about respondent personal beliefs and habits showed that organic respondents were more likely $(P<0.05)$ to report that they felt they consumed a "healthy" diet, whereas nonorganic consumers were more likely $(P<0.05)$ to report "balanced" dietary habits.
Overall, the top motivating concepts reported by organic users were, in order, "Organic milk is healthier for me," "Organic milk encourages the ethical treatment of animals," and "Organic milk production supports local farms and farmers." The notion of organic milk being a healthier option (compared with conventional milk) was rated as the leading reason for organic purchase and mirrored the self-reported dietary habits of the organic user group; however, it is arguably the most misled conclusion, as the nutritional equivalence of organic and conventional milk has been addressed extensively (Woese et al., 1997; Kouba, 2003). Interestingly, the idea of organic milk purchase as a passively benevolent act (ethical animal treatment, local farm/farmer support, environmental sustainability) was reported as a highly motivating factor behind organic purchase, accounting for $35.1 \%$ of the purchase reasoning on average. Beliefs concerning animal welfare and the environment have consistently been cited as motivations for consumers to explore substitutes to conventional fluid milk, such as plant-based alternatives (McCarthy et al., 2017b). However, for fluid milk, it is hypothesized that some consumers equate organic designation with practices such as free-range farming, rbST-free, or both, and are willing to pay a price premium to assuage these concerns (Harper and Makatouni, 2002; Hill and Lynchehaun, 2002; Conner and Oppenheim, 2008). In addition, sentiments regarding desire to support local farms were particularly strong among organic consumers, accounting for $12.08 \%$ of organic dairy purchase reasoning among tested issues or beliefs. Outside of willingness-to-pay and valuation studies, very little is known about the perception of local designation as it relates to fluid milk. Choice experiments on blackberry preserves by Meas et al. (2014) suggested that consumer opinions of local products typically overlapped with

Table 4. Maximum difference scaling of reasons for organic milk purchase by organic milk users $(\mathrm{n}=434)^{1}$

\begin{tabular}{lc}
\hline Label $^{2}$ & Average \\
\hline Organic milk is healthier for me & $16.83^{\mathrm{a}}$ \\
Organic milk production encourages the ethical treatment of animals & $12.47^{\mathrm{b}}$ \\
Organic milk production supports local farms and farmers & $12.08^{\mathrm{b}}$ \\
Organic milk is all-natural & $11.81^{\mathrm{bc}}$ \\
Organic milk production promotes environmental sustainability & $10.55^{\mathrm{c}}$ \\
Organic milk is a higher quality product than conventional milk & $9.07^{\mathrm{d}}$ \\
Organic milk tastes better & $7.76^{\mathrm{d}}$ \\
Organic milk is rbST-free & $6.37^{\mathrm{e}}$ \\
Organic milk is non-GMO & $5.30^{\mathrm{e}}$ \\
Organic milk is a premium product & $3.35^{\mathrm{f}}$ \\
Organic milk is part of my dietary habits (I always eat organic) & $3.01^{\mathrm{f}}$ \\
Organic milk is more available than other types of milk & $1.40^{\mathrm{g}}$ \\
\hline
\end{tabular}

${ }^{\mathrm{a}-\mathrm{g}}$ Means in a row with a different superscript letter are different $(P<0.05)$.

${ }^{1}$ Sum of column values is 100 total points, and results are interpreted as ratio-scaled values.

${ }^{2} \mathrm{rbST}=$ recombinant bovine somatotropin; GMO = genetically modified organism. 
a)

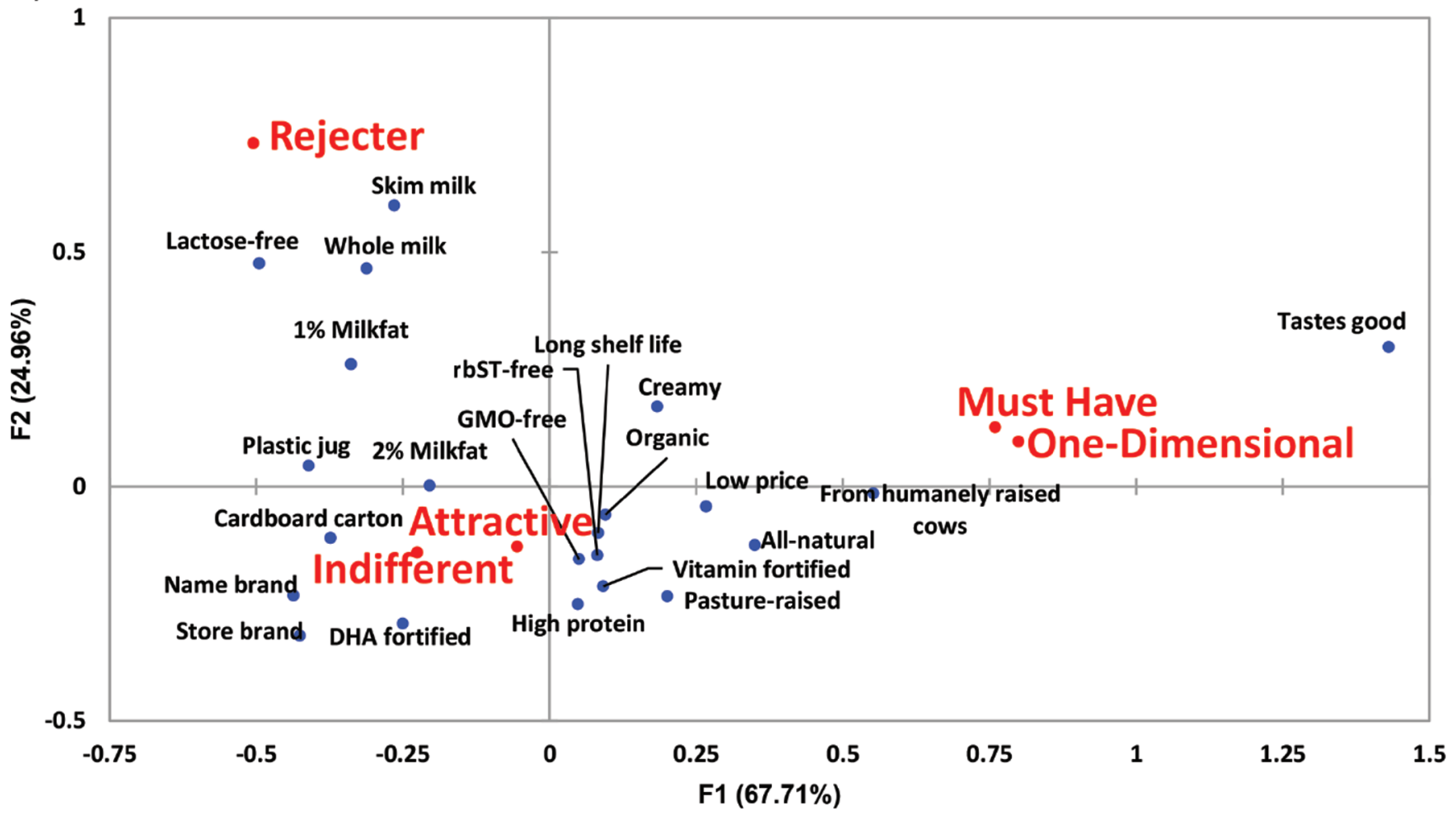

b)

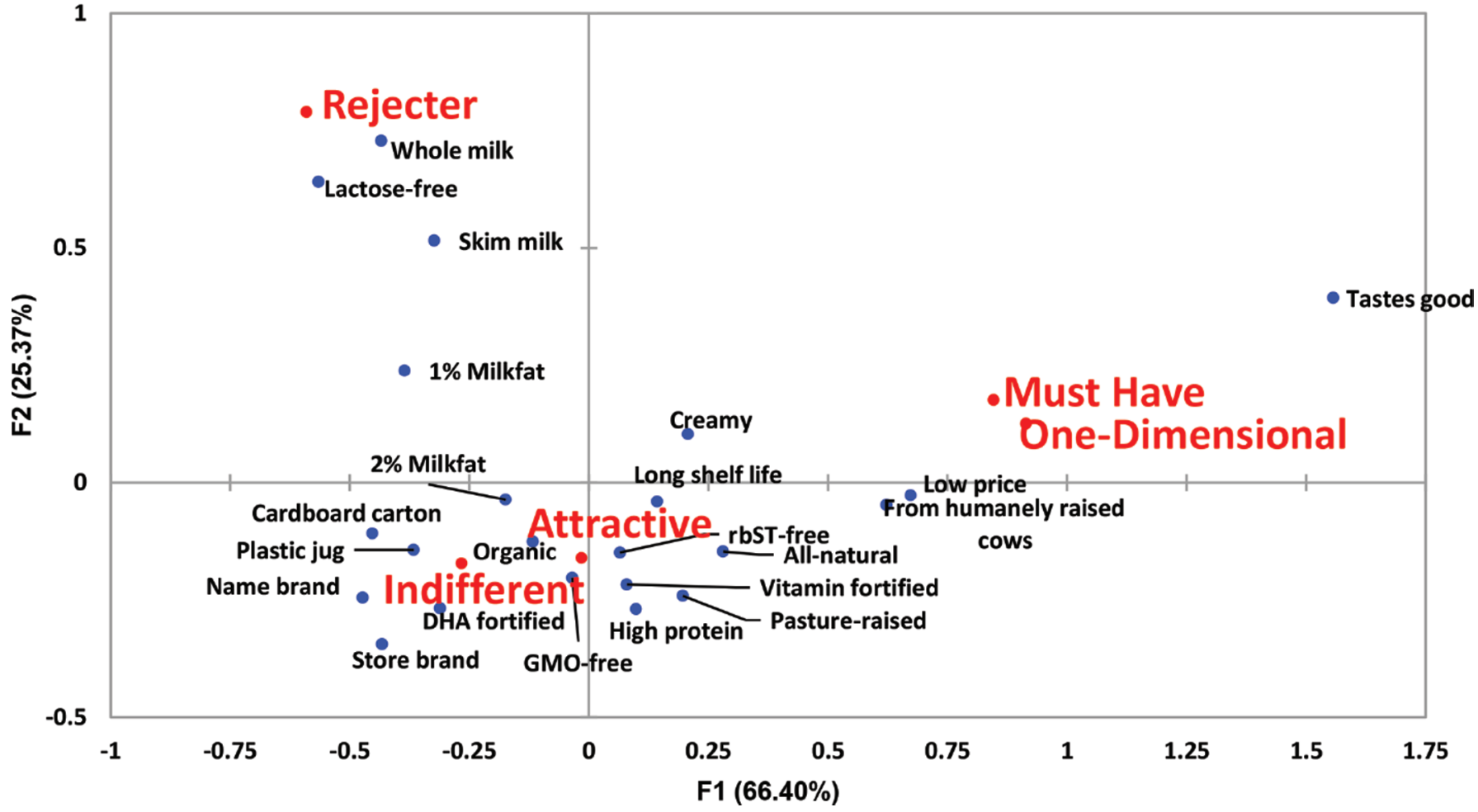

Figure 5. (a) Correspondence analysis biplot of Kano analysis counts for premium cluster ( $\mathrm{n}=352$ ) of fluid milk consumers. (b) Correspondence analysis biplot of Kano analysis counts for opportunistic cluster $(\mathrm{n}=393)$ of fluid milk consumers. (c) Correspondence analysis biplot of Kano analysis counts for value cluster $(\mathrm{n}=234)$ of fluid milk consumers. (d) Correspondence analysis biplot of Kano analysis counts for basics cluster $(\mathrm{n}=184)$ of fluid milk consumers. DHA = docosahexaenoic acid; GMO = genetically modified organism; rbST $=$ recombinant bovine somatotropin. Color version available online. 
c)

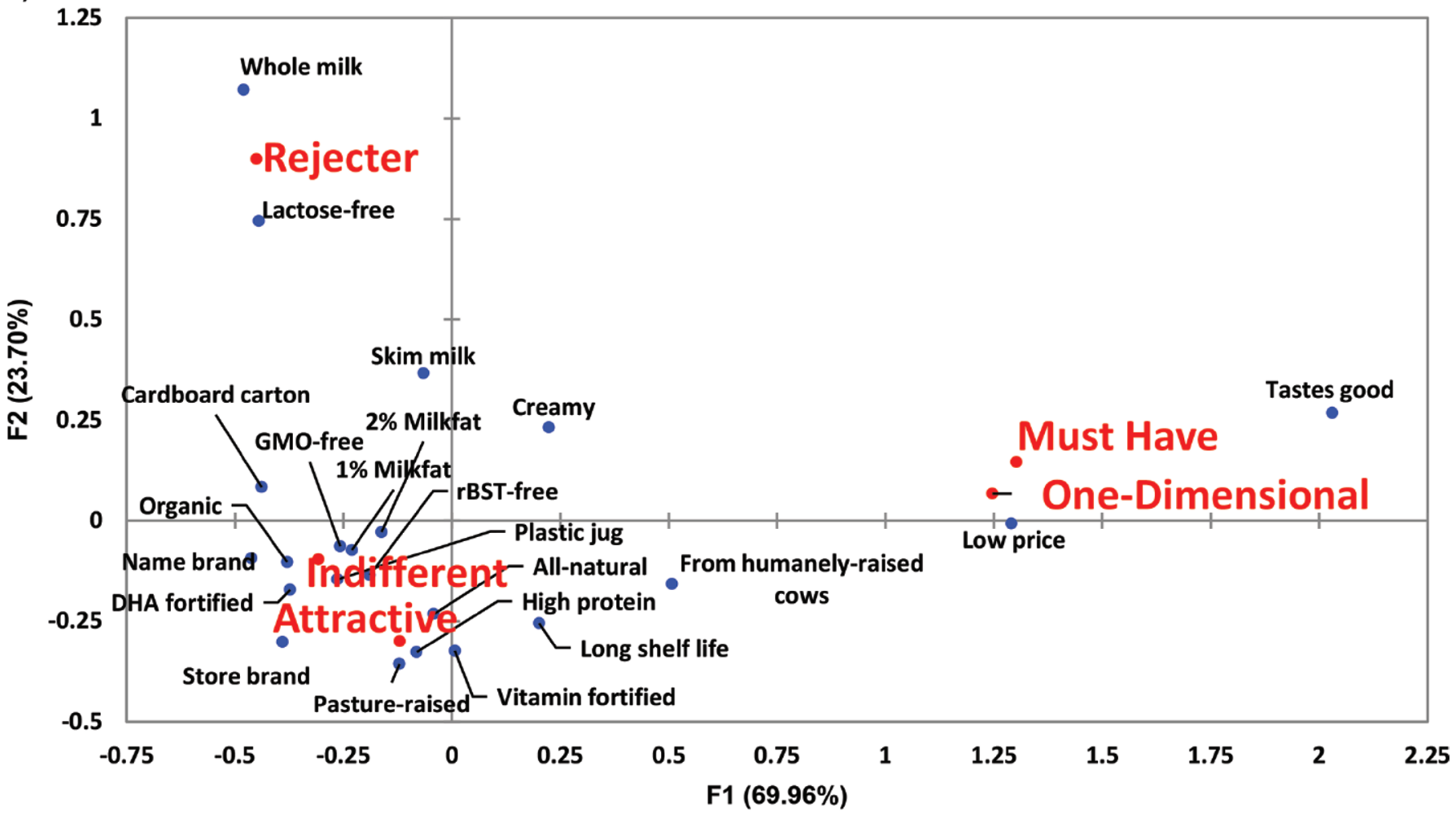

d)

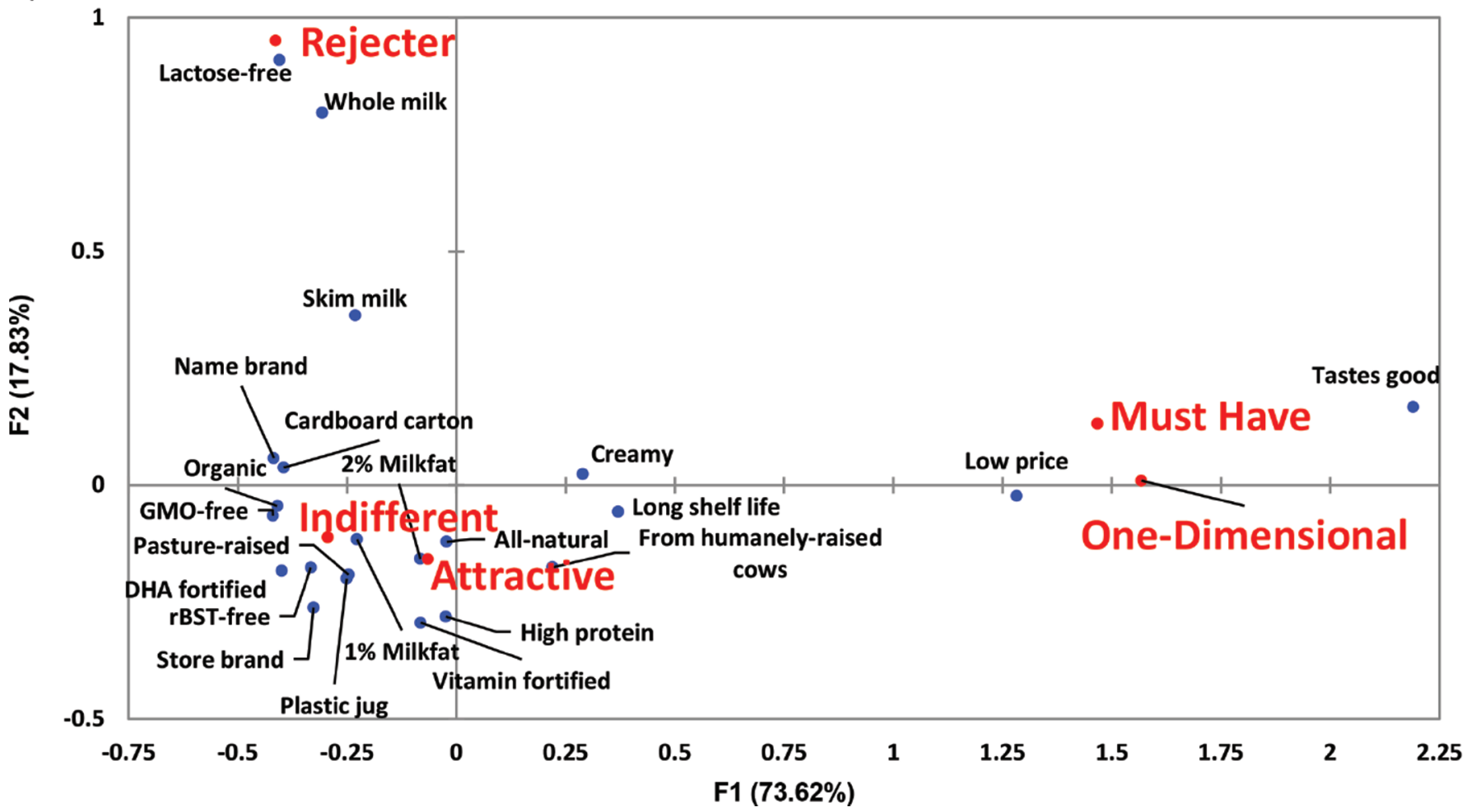

Figure 5 (Continued). (a) Correspondence analysis biplot of Kano analysis counts for premium cluster $(\mathrm{n}=352)$ of fluid milk consumers. (b) Correspondence analysis biplot of Kano analysis counts for opportunistic cluster ( $\mathrm{n}=393$ ) of fluid milk consumers. (c) Correspondence analysis biplot of Kano analysis counts for value cluster $(\mathrm{n}=234)$ of fluid milk consumers. (d) Correspondence analysis biplot of Kano analysis counts for basics cluster $(\mathrm{n}=184)$ of fluid milk consumers. DHA = docosahexaenoic acid; GMO = genetically modified organism; rbST = recombinant bovine somatotropin. Color version available online. 
organic designation. Furthermore, conjoint experiments by Darby et al. (2008) suggested that consumers typically believed "local" to be interchangeable with terms such as "nearby" or "in-state" for produce products. Although it is likely that a similar overlap and understanding of local products may exist for fluid milk, the subject is largely unknown and is an area that requires further investigation. Overall, results of this MaxDiff analysis suggest that although the idea of health/nutritional promotion is the leading reason for organic milk purchase, appeals to ideals outside of nutrition are also effective motivators. Furthermore, it is important to note that the ideals of animal welfare, local farm support, and environmental consciousness are not exclusive to organic fluid milk products alone and may impart a perceived added value on their own merits. Consumer education and effective product positioning may provide further benefits to the fluid milk industry.

\section{Kano Model}

Kano analysis results were analyzed within the clusters derived from conjoint utility scores (Figures 5a-d). Overall, each cluster defined the majority of fluid milk features as being "indifferent" attributes, with the exception of "milk that tastes good," which was chosen as an "one-dimensional" attribute by each cluster. To further understand underlying trends that defined each cluster, CA was applied to each cluster Kano analysis count data. Correspondence analysis was used due to the fact that the Kano model is susceptible to having products described by multiple similar categorizations, which may result in misclassification (Sauerwein et al., 1996). Because the full spectrum of Kano categorizations is figured into CA biplots, a more clear representation of consumer sentiments is preserved. Results showed that premium cluster respondents (Figure 5a) strongly associated low price and humanely raised cows with must-have or one-dimensional classification, which was not shown in classical Kano categorization alone. In addition, attributes such as lactose-free, whole milk, and skim milk were associated strongly with rejecter classification, and attributes such as organic, GMOfree, high protein, and pasture-raised showed modest classification as attractive. For the opportunistic cluster (Figure 5b), a strong association was observed between must-have/one-dimensional characterization and features such as low price and humanely raised cows, similar to the premium cluster. Like the premium cluster, the opportunistic cluster also exhibited strong association between rejecter attribute characterization and features such as whole milk and lactose-free. The sentiment of whole milk as a rejecter attribute is in line with current market standings; however, the universal dislike of lactose-free milk is likely because lactose-free milk products violate "all-natural" classification, which is a leading motivator for fluid milk purchase (McCarthy et al., 2017b). The opportunistic cluster differentiated itself from the premium cluster by associating attributes such as organic and GMO-free with relatively greater indifference. Evaluation of Kano results from the value cluster (Figure 5c) was characterized by strong rejection for whole milk, indifference for skim milk relative to premium and opportunistic cluster respondents, and a strong association between price and one-dimensional characterization. Furthermore, value cluster members showed little differentiation in attribute characterization as indifferent or attractive, suggesting that they felt no attributes warranted sentiment of added value. This included the "all-natural" designation, which was perceived as more of a one-dimensional/must-have attribute in the premium and opportunistic clusters. Value cluster respondents exhibit a modest association of attractive characterization with pasture-raised and high protein features. Results from the basics cluster (Figure 5d) showed similar tendencies to the value cluster. The basics cluster was differentiated from other clusters by associating label claim features, such as GMO-free, pasture-raised, DHA-fortified, rbST-free, all-natural, and organic, with relatively more indifference and less attractive characterization. In general, these results validated conjoint utility estimation of price by cluster (Figure 4), with the premium and opportunistic clusters showing less indifference to value-added features, and value and basics clusters associating value-added features that may suggest higher prices with indifference. In addition, value and basics cluster respondents were relatively more interested in long shelf-life, compared with premium and opportunistic cluster members, although they assigned a lower importance score for the shelf-life attribute in the conjoint exercise. This inconsistency suggests that some consumer clusters may be unfamiliar with nonconventional pasteurization techniques and the shelf-life benefits they convey and indicates that further education of fluid milk consumers is warranted.

\section{CONCLUSIONS}

Fluid milk is primarily viewed as a staple product, meaning its value is typically derivative of its utility. This belief is reflected in the overall population disproportional emphasis on attributes such as milkfat (nutrition) and price; however, unique attribute levels are clearly differentiators of purchase for certain consumer clusters. Premium cluster respondents expressed 
interest in milk categories outside of convention such as organic and pasture-raised, the opportunistic cluster was characterized by interest in locally farmed milk and moderate interest in added-value attributes, the value cluster expressed interest in locally farmed milk, but was ultimately very price sensitive, and the basics cluster was almost entirely price-focused except for a slight interest in product details such as taste, package, size, and brand. Evaluation of demographics by cluster also suggested that factors such as income, education, and lifestyle habits may be significant indicators of ultimate purchase habits. For organic fluid milk consumers, several different factors motivate the purchase of organic milk and dairy products. Many of the issues influencing organic consumers are rooted in the idea of enhanced nutrition/well-being, or beliefs of benevolence, such as environmental sustainability, ethical animal treatment, or local farm support. Utilization of sentiments from organic fluid milk consumers may act as guidance for marketing and education initiatives and may help product developers and fluid milk producers to better meet the needs of consumers in today's market.

\section{ACKNOWLEDGMENTS}

Funding was provided in part by the National Dairy Council (Rosemont, IL). The use of trade names does not imply endorsement or lack of endorsement of those not mentioned.

\section{REFERENCES}

Alviola, P. A., and O. Capps. 2010. Household demand analysis of organic and conventional fluid milk in the United States based on the 2004 Nielsen Homescan panel. Agribusiness 26:369-388.

Bakke, A. J., C. V. Shehan, and J. E. Hayes. 2016. Type of milk typically consumed, and stated preference, but not health consciousness affect revealed preferences for fat in milk. Food Qual. Prefer. 49:92-99.

Bernard, J. C., and D. J. Bernard. 2009. What is it about organic milk? An experimental analysis. Am. J. Agric. Econ. 91:826-836.

Chang, C. H., N. H. Hooker, E. Jones, and A. Sam. 2011. Organic and conventional milk purchase behaviors in Central Ohio. Agribusiness 27:311-326.

Chapman, C. N., J. L. Alford, C. Johnson, R. Weidemann, and M. Lahav. 2009. CBC vs. ACBC: Comparing results with real product selection. Pages 199-206 in Sawtooth Software Inc. 2009 Sawtooth Software Conference Proceedings; Mar 25-27; Delray Beach, FL.

Chrysochou, P. 2014. Drink to get drunk or stay healthy? Exploring consumers' perceptions, motives and preferences for light beer. Food Qual. Prefer. 31:156-163.

Conner, D. S., and D. Oppenheim. 2008. Demand for pasture-raised livestock products: Results from Michigan retail surveys. J. Agribusiness 26:1-20.

Cunningham, C. E., K. Deal, and Y. Chen. 2010. Adaptive choicebased conjoint analysis: A new patient-centered approach to the assessment of health service preferences. Patient 3:257-273.

Darby, K., M. T. Batte, S. Ernst, and B. Roe. 2008. Decomposing local: A conjoint analysis of locally produced foods. Am. J. Agric. Econ. 90:476-486.
DMI. 2017. DMI quarterly retail snapshot: Milk Q2 2017. Dairy Management Inc., Rosemont, IL.

Goodman, S., L. Lockshin, and E. Cohen. 2005. Best-worst scaling: a simple method to determine drinks and wine style preferences. International Wine Marketing Symposium 2005 Proceedings; July 8-9; Sonoma, CA.

Harper, G. C., and A. Makatouni. 2002. Consumer perception of organic food production and farm animal welfare. Br. Food J. 104:287-299.

Hill, H., and F. Lynchehaun. 2002. Organic milk: Attitudes and consumption patterns. Br. Food J. 104:526-542.

Hubbard, E. M., S. M. Jervis, and M. A. Drake. 2016. The effect of extrinsic attributes on liking of cottage cheese. J. Dairy Sci. 99:183-193.

Jervis, S. M., J. M. Ennis, and M. A. Drake. 2012. A comparison of adaptive choice-based conjoint and choice-based conjoint to determine key choice attributes of sour cream with limited sample size. J. Sens. Stud. 27:451-462.

Jones, E., C. Akbay, B. Roe, and W. S. Chern. 2003. Analyses of consumers' dietary behavior: An application of the AIDS model to supermarket scanner data. Agribusiness 19:203-221.

Kano, N., N. Seraku, F. Takahashi, and S. Tsuji. 1984. Attractive quality and must be quality. J. Jpn. Soc. Qual. Control. 14:147-156.

Kim, M. K., K. Lopetcharat, and M. A. Drake. 2013. Influence of packaging information on consumer liking of chocolate milk. J. Dairy Sci. 96:4843-4856.

Kolodinsky, J. 2008. Affect or information? Labeling policy and consumer valuation of rBST free and organic characteristics of milk. Food Policy 33:616-623.

Kouba, M. 2003. Quality of organic animal products. Livest. Sci. $80: 33-40$.

Kuo, C. M., S. H. You, and C. Y. Lu. 2014. Integration of the Kano and QFD model in health food development: Using black beans as examples. Qual. Quant. 48:225-242.

Lee, A. P., D. M. Barbano, and M. A. Drake. 2017. The influence of ultra-pasteurization by indirect heating versus direct steam injection on skim and 2\% fat milks. J. Dairy Sci. 100:1688-1701.

Li, X. E., K. Lopetcharat, and M. A. Drake. 2014. Extrinsic attributes that influence parents' purchase of chocolate milk for their children. J. Food Sci. 79:S1407-S1415.

Lillestøl, J. 1991. Multivariate statistical methods for quality creation: A review. Total Qual. Manag. Bus. 2:291-304.

Lofgren, M., and L. Witell. 2008. Two decades of using Kano's theory of attractive quality: A literature review. Qual. Manag. J. 15:59-75.

Louviere, J. J., and G. G. Woodworth. 1990. Best-worst scaling: A model for largest difference judgments. Working Paper, Department of Marketing and Economic Analysis, Univ. of Alberta, Canada.

Lusk, J. L., and N. Parker. 2009. Consumer preferences for amount and type of fat in ground beef. J. Agric. Appl. Econ. 41:75-90.

McCarthy, K. S., K. Lopetcharat, and M. A. Drake. 2017a. Milk fat threshold determination and the effect of milk fat content on consumer preference for fluid milk. J. Dairy Sci. 100:1702-1711.

McCarthy, K. S., M. Parker, A. Ameerally, S. L. Drake, and M. A. Drake. 2017b. Drivers of choice for fluid milk versus plant-based alternatives: What are consumer perceptions of fluid milk? J. Dairy Sci. 100:6125-6138.

McLean, K. G., D. J. Hanson, S. M. Jervis, and M. A. Drake. 2017. Consumer perception of retail pork bacon attributes using adaptive choice-based conjoint analysis and maximum differential scaling. J. Food Sci. 82:2659-2668.

Meas, T., W. Hu, M. T. Batte, T. A. Woods, and S. Ernst. 2014. Substitutes or complements? Consumer preference for local and organic food attributes. Am. J. Agric. Econ. 97:1044-1071.

Oltman, A. E., K. Lopetcharat, E. Bastian, and M. A. Drake. 2015. Identifying key attributes for protein beverages. J. Food Sci. 80:S1383-S1390.

Orme, B. K. 2009. Fine-tuning CBC and adaptive CBC questionnaires. Sawtooth Software Research Paper Series. Sawtooth Software, Sequim, WA. 
Orme, B. K. 2010. Pages 19-50 in Getting started with conjoint analysis: Strategies for product design and pricing research. Research Publishers LLC, Madison, WI.

OTA. 2017. U.S. Organic Industry Survey 2017. Organic Trade Association, Washington, DC.

Oupadissakoon, G., D. H. Chambers, and E. Chambers IV.. 2009 Comparison of the sensory properties of ultra-high-temperature (UHT) milk from different countries. J. Sens. Stud. 24:427-440.

Paul, J., and J. Rana. 2012. Consumer behavior and purchase intention for organic food. J. Consum. Mark. 29:412-422.

Sauerwein, E., F. Bailom, K. Matzler, and H. H. Hinterhuber. 1996. The Kano model: How to delight your customers. International Working Seminar on Production Economics 1:313-327.

Schott, L., and J. Bernard. 2015. Comparing consumer's willingness to pay for conventional, non-certified organic and organic milk from small and large farms. J. Food Distrib. Res. 46:186-205.

Smith, T. A., C. L. Huang, and B. H. Lin. 2009. Estimating organic premiums in the US fluid milk market. Renew. Agric. Food Syst. 24:197-204.
Wardy, W., B. Mena, S. Nongtaodum, H. K. No, and W. Prinyawiwatkul. 2014. Exploring the drivers of purchase intent and consumer satisfaction of chicken eggs using principal component analysis and the Kano model. J. Sens. Stud. 29:463-473.

Woese, K., D. Lange, C. Boess, and K. W. Bögl. 1997. A comparison of organically and conventionally grown foods-Results of a review of the relevant literature. J. Sci. Food Agric. 74:281-293.

Wolf, C. A., G. T. Tonsor, and N. J. Olynk. 2011. Understanding US consumer demand for milk production attributes. J. Agric. Resour. Econ. 36:326-342.

Xu, Q., R. J. Jiao, X. Yang, M. Helander, H. M. Khalid, and A. Opperud. 2009. An analytical Kano model for customer need analysis. Des. Stud. 30:87-110.

Zepeda, L., R. Douthitt, and S. Y. You. 2003. Consumer risk perceptions toward agricultural biotechnology, self-protection, and food demand: The case of milk in the United States. Risk Anal. 23:973-984.

Zepeda, L., and C. Leviten-Reid. 2004. Consumers' views on local food. J. Food Distrib. Res. 35:1-6. 